18. Ajit et al., Modeling analysis of potential carbon sequestration under existing agroforestry systems in three districts of IndoGangetic plains in India. Agrofor. Syst., 2013, 87, 1129-1146.

19. Thevathasan, N. V. and Gordon, A. M., Poplar leaf biomass distribution and nitrogen dynamics in a poplar-barley intercropped system in southern Ontario, Canada. Agrofor. Syst., 1997, 37(1), 79-90.

20. Yadav, R. P., Bisht, J. K. and Bhatt, J. C., Biomass, carbon stock under different production systems in the mid-hills of Indian Himalaya. Trop. Ecol., 2017, 58(1), 15-21.

21. Wani, N., Velmurugan, A. and Dadhwal, V. K., Assessment of agricultural crop and soil carbon pools in Madhya Pradesh, India. Trop. Ecol., 2010, 51, 11-19.

22. Kaul, M., Mohren, G. M. J. and Dadhwal, V. K., Carbon storage and sequestration potential of selected tree species in India. Mitig. Adapt. Strat. Global Climate Change, 2013, 15, 489-510.

23. Nair, P. K. R. and Garrity, D., Agroforestry research and development: the way forward. In Agroforestry - The Future of Global Land Use (eds Nair, P. K. R. and Garrity, D.), Springer, Dordrecht, The Netherlands, 2012, pp. 515-531.

24. Gera, M., Mohan, G., Bisht, N. S. and Gera, N., Carbon sequestration potential of agroforestry under CDM in Punjab state of India. Indian J. For., 2011, 34, 1-10.

25. Schmidt, M. W. I. et al., Persistence of soil organic matter as an ecosystem property. Nature, 2011, 478, 49-56.

26. Torn, M. S., Swanston, C. W., Castanha, C. and Trumbore, S. E., Storage and turnover of natural organic matter in soil. In Biophysico-Chemical Processes Involving Natural Nonliving Organic Matter in Environmental Systems (eds Senesi, N., Xing, B. and Huang, P. M.), Wiley, Hoboken, NJ, USA, 2009, pp. 219-272.

27. Lal, R., Soil carbon sequestration in natural and managed tropical forest ecosystems. J. Sustain. For., 2005, 21, 1-30.

28. Gentile, R., Vanlauwe, B. and Six, J., Litter quality impacts shortbut not long-term soil carbon dynamics in soil aggregate fractions. Ecol. Appl., 2011, 21, 695-703.

29. Shi, S., Zhang, W., Zhang, P., Yu, Y. and Ding, F., A synthesis of change in deep soil organic carbon stores with afforestation of agricultural soils. For. Ecol. Manage., 2013, 296, 53-63.

30. Lorenz, K. and Lal, R., Carbon Sequestration in Forest Ecosystems, Springer, Dordrecht, The Netherlands, 2010.

31. Kell, D. B., Large-scale sequestration of atmospheric carbon via plant roots in natural and agricultural ecosystems: why and how. Philos. Trans. R. Soc. London, Ser. B., 2012, 367, 1589-1597.

32. Laganière, J., Angers, D. and Paré, D., Carbon accumulation in agricultural soils after afforestation: a meta-analysis. Global Change Biol., 2010, 16, 439-453.

Received 4 October 2020; revised accepted 18 January 2021

\section{BDNF protects photoreceptors from light-induced oxidative stress through upregulating CERKL in vitro}

\author{
Qianwen $\mathrm{He}^{1, \#}$, Juan Yang ${ }^{2, \#}$, Mengting Gao ${ }^{3}$ \\ and Yinxian Wen ${ }^{4, *}$ \\ ${ }^{1}$ Department of Anesthesiology, Zhongnan Hospital of Wuhan \\ University, Wuhan 430071, China \\ ${ }^{2}$ Department of Operations Management, Zhongnan Hospital of \\ Wuhan University, Wuhan 430071, China \\ ${ }^{3}$ Department of Statistics, Renmin Hospital of Wuhan University, \\ Wuhan 430071, China \\ ${ }^{4}$ Department of Orthopedic Surgery, Zhongnan Hospital of \\ Wuhan University, Wuhan 430071, China
}

Brain-derived neurotrophic factor (BDNF) protects the retina from light-induced injury. In this study, white light suppressed the cell viability of $661 \mathrm{~W}$ photoreceptor cells in a time- and intensity-dependent manner, decreased the mRNA and protein levels of ceramide kinase-like (CERKL), but increased the reactive oxygen species (ROS) content in $24 \mathrm{~h}$. Decrease in ROS content and increase in CERKL level were detected after BDNF treatment. BDNF also attenuated the light-induced ROS accumulation, as well as cell viability and CERKL suppression. Thus, strong light causes CERKL suppression, ROS accumulation and the consequent attenuation of photoreceptor viability, while BDNF protects it from such injuries through upregulating CERKL expression and downregulating $R O S$ accumulation.

Keywords: Brain-derived neurotrophic factor, ceramide kinase-like, light-induced injury, photoreceptors, reactive oxygen species.

RETINAL degeneration, such as retinitis pigmentosa and age-related macular degeneration, is a retinopathy typically characterized by pathological loss of highly differentiated cells, especially photoreceptor cells, which may lead to irreversible visual impairment and even blindness ${ }^{1}$. Although the incidence is high and keeps rising, there is currently no effective treatment for retinal degeneration.

A wide variety of causes have been proved to attribute to retinal degeneration, among which retinal light injury is regarded as an important factor. In the retina, prolonged or high-intensity exposure to visible light results in apoptosis of photoreceptor cells, and development of intracellular reactive oxygen species (ROS) and lipid peroxidation ${ }^{2}$. The accumulation of ROS in the photoreceptors is one of the major pathophysiological changes in the light-induced retinal degeneration ${ }^{3-5}$, which further leads to apoptosis of photoreceptor cells and eventually blindness.

*For correspondence. (e-mail: wenyinxian@whu.edu.cn)

${ }^{*}$ Contributed equally to this work. 
RESEARCH COMMUNICATIONS

Table 1. Primers for real-time PCR and the reaction conditions

\begin{tabular}{lcccc}
\hline & & \multicolumn{2}{c}{ Sequence } & \\
\cline { 2 - 5 } Target genes & Forward & Reverse & Annealing & Product size (bp) \\
\hline GAPDH & CCCTTAAGAGGGATGCTGCC & ACTGTGCCGTTGAATTTGCC & $60^{\circ} \mathrm{C}, 15 \mathrm{sec}$ & 263 \\
CERKL & ATGGCACCCAGAGGCTTTAC & TGGGTGCAGCCTAATGTGAA & $60^{\circ} \mathrm{C}, 30 \mathrm{sec}$ & 318 \\
\hline
\end{tabular}

GAPDH, Glyceraldehyde phosphate dehydrogenase; CERKL, Ceramide kinase-like.

Ceramide kinase-like (CERKL) is essential for retinal development, protecting the retinal cells from excessive oxidative stress-induced apoptosis. CERKL gene mutations are associated with severe retinal degeneration, with early and prominent loss of macular cone and rod photoreceptors $^{6-8}$. It is also reported that CERKL mutations are related to widespread retinal degeneration with prominent early maculopathy ${ }^{9,10}$.

As a member of the neurotrophin family of growth factors, brain-derived neurotrophic factor (BDNF) is demonstrated to be neuroprotective for photoreceptor cells ${ }^{11}$. Evidences indicate that BDNF may rescue photoreceptor via the microglia-Muller glia network ${ }^{12}$. It has also been reported that BDNF gene transfection could defend photoreceptors against light-induced injury ${ }^{13}$.

In this study, we aim to explore the effect of BDNF on the light-induced retinal injury and the underlying mechanisms involving CERKL and ROS.

DMEM/F12 (1:1) and fetal bovine serum (FBS) were purchased from Thermo Scientific (MA, USA). Recombinant mouse BDNF was supplied by PeproTech (NJ, USA). Cell counting Kit-8 (CCK-8) was obtained from Dojindo Molecular Technologies (MD, USA). TRIzol reagent was acquired from Life Technologies (CA, USA). First Strand cDNA Synthesis Kit and RT-PCR kit were obtained from Takara Biotechnology (WI, USA). Sangon Biotech (Shanghai, China) synthesized the oligonucleotide primers. Antibodies and Western Bright ECL HRP substrate were purchased from Proteintech and Advansta (CA, USA). BCA Protein Assay Kit, ROS Assay Kit and RIPA lysis buffer were supplied by Beyotime Institute of Biotechnology (Shanghai, China). Other reagents and chemicals were of analytical grade.

The $661 \mathrm{~W}$ photoreceptor cells were cultured in DMEM/F12 (1:1) supplemented with 10\% (v/v) FBS, $100 \mathrm{IU} / \mathrm{ml}$ penicillin, $100 \mathrm{mg} / \mathrm{ml}$ streptomycin and $2 \mathrm{mM}$ glutamine in a $5 \% \mathrm{CO}_{2}$ atmosphere at $37^{\circ} \mathrm{C}$. The $661 \mathrm{~W}$ photoreceptor cells were treated with $0,2500,5000$ and 10,000 lux white light for $0,6,12$ and $24 \mathrm{~h}$ and cell viability was assessed. Meanwhile, ROS concentration and CERKL expression were also detected after the cells were treated with light of 2500 lux for $0,6,12$ and $24 \mathrm{~h}$, and with 2500 lux light or/and BDNF for $24 \mathrm{~h}$.

The $661 \mathrm{~W}$ photoreceptor cells were cultured in 96-well plates at $1 \times 10^{4}$ cells $/ \mathrm{ml}$ and treated as described above. Then the medium was replaced with $100 \mu \mathrm{l}$ serum-free DMEM/F12 containing $10 \mu \mathrm{l}$ CK- 8 reagent. The absor- bance of each well was measured by a UV-1601 spectrophotometer (Shimadzu, Kyoto, Japan) at $450 \mathrm{~nm}$.

ROS content was assessed using the ROS assay kit, according to the manufacturer's protocol. The $661 \mathrm{~W}$ photoreceptor cells were cultured with DCFH-DA for $20 \mathrm{~min}$ at $37^{\circ} \mathrm{C}$. Fluorescence was measured by a flow cytometer, with a $488 \mathrm{~nm}$ excitation wavelength and a $525 \mathrm{~nm}$ emission wavelength.

Total RNA was extracted from the $661 \mathrm{~W}$ photoreceptor cells using TRIzol reagent, according to the manufacturer's instructions. Single-strand cDNA was obtained from purified total RNA using the reverse transcription kit. Primers utilized in the present study were designed using the NCBI BLAST database and Primer Premier 5.0 (Premier Biosoft, CA, USA). Table 1 lists the optimal PCR conditions and primer sequences. The StepOne thermal cycler (Applied Biosystems, NY, USA) was used to perform the RT-PCR assay, according to the following procedure: $30 \mathrm{sec}$ pre-denaturation at $95^{\circ} \mathrm{C}, 5 \mathrm{sec}$ denaturation at $95^{\circ} \mathrm{C}, 30 \mathrm{sec}$ annealing at melting temperature $\left(T_{\mathrm{m}}\right)$ and $30 \mathrm{sec}$ extension at $72^{\circ} \mathrm{C}$. Forty cycles were required for the last three steps. Relative standard curves were used to quantify the mRNA level of each sample, while the mRNA level of GAPDH was detected and applied as an internal control.

The $661 \mathrm{~W}$ photoreceptor cells were lysed in the RIPA lysis buffer. Total proteins were harvested and quantified using a BCA kit, according to the instructions. The protein samples were loaded as $40 \mu \mathrm{g}$ per lane, separated by $5 \%$ and $10 \%$ SDS-PAGE gradient electrophoresis and then blotted onto nitrocellulose membranes. The membranes were blocked in 5\% skimmed milk, probed with primary antibodies (anti-CERKL $(1: 500)$ and GAPDH $(1: 1000))$, incubated with horseradish peroxidaseconjugated secondary antibody (goat anti-rabbit IgG, $1: 5000$ ) and visualized using ECL HRP substrate. Then, relative protein level was obtained by quantifying the blots via densitometry using Quantity One software (version 4.6, Bio-Rad Laboratories Inc., CA, USA). The value of each group was standardized with the control and subsequently the GAPDH protein level.

Statistical analysis was performed using SPSS 17.0 software (SPSS Science Inc., Chicago City, USA) and Prism 5.0 software (GraphPad Software, CA, USA). The data were presented as mean \pm standard deviation (SD). Student's $t$ test was performed in paired analyses, while analysis of variance (ANOVA) was performed between 
groups. The level of $P<0.05$ was considered statistically significant.

The $661 \mathrm{~W}$ photoreceptor cells were treated with different doses of white light for different durations. After $24 \mathrm{~h}$ stimulation with 2500, 5000 and 10000 lux, cell viability was significantly reduced compared to control group $(P<0.05)$, while even $12 \mathrm{~h}$ stimulation could decrease cell viability when the dose of white light was high enough (10,000 lux). As shown in Figure 1 the reduction of cell viability in $661 \mathrm{~W}$ photoreceptor cells was intensitydependent $(P<0.05)$.

The $661 \mathrm{~W}$ photoreceptor cells were treated with 2500 lux white light for $0,6,12$ and $24 \mathrm{~h}$. It was found that ROS level of the cells increased with the prolongation of stimulation time, which was significantly higher than that of the control at 12 and $24 \mathrm{~h}$ (Figure $2 a$, $P<0.01)$. mRNA of CERKL gene was significantly downregulated at $24 \mathrm{~h}$ (Figure $2 b, P<0.05$ ), and protein level was also downregulated in a time-dependent manner (Figure $2 b$ ).

The $661 \mathrm{~W}$ photoreceptor cells were incubated with 10 , 50 and $250 \mathrm{ng} / \mathrm{ml}$ BDNF for $24 \mathrm{~h}$. BDNF downregulated ROS content of these cells in a concentration-dependent manner, especially at 50 and $250 \mathrm{ng} / \mathrm{ml}$ concentrations (Figure $3 a, P<0.05$ ). BDNF upregulated the expression

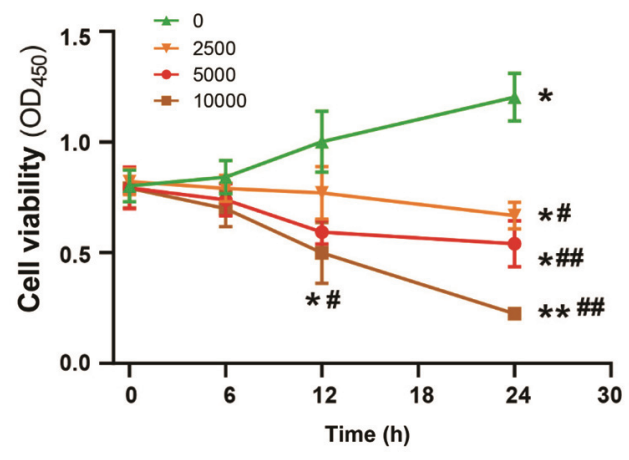

Figure 1. Cell viability of $661 \mathrm{~W}$ photoreceptor cells. These cells were treated with $0,2500,5000$ and 10,000 lux white light for $0,6,12$ and $24 \mathrm{~h} . * P<0.05, * * P<0.01$ versus $0 \mathrm{~h}$ at the same strength of light exposure; ${ }^{\#} P<0.05,{ }^{\#} P<0.01$ versus 0 lux at the same time. $N \geq 5$. (a)

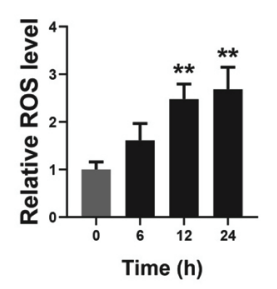

(b)

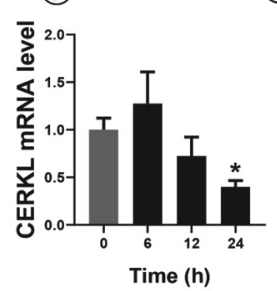

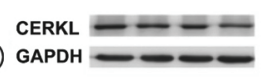

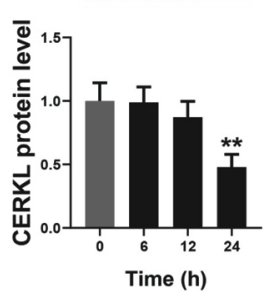

Figure 2. Reactive oxygen species (ROS) and ceramide kinase-like (CERKL) gene expression. The cells were treated with light of 2500 lux for $0,6,12$ and 24 h. $\boldsymbol{a}$, ROS content in the $661 \mathrm{~W}$ cells; $\boldsymbol{b}$, mRNA level of CERKL in the $661 \mathrm{~W}$ cells; $\boldsymbol{c}$, Protein level of CERKL in the $661 \mathrm{~W}$ cells. ${ }^{*} P<0.05,{ }^{*} P P<0.01$ versus control. $N \geq 3$. of CERKL mRNA and protein in a concentrationdependent manner, while the mRNA level of CERKL was statistically increased when BDNF concentration increased to $250 \mathrm{ng} / \mathrm{ml}$ (Figure $3 b, P<0.01$ ).

The $661 \mathrm{~W}$ photoreceptor cells were treated with 2500 lux light or/and $250 \mathrm{ng} / \mathrm{ml} \mathrm{BDNF}$ for $24 \mathrm{~h}$. As shown in Figure 4, the CERKL mRNA level and cell viability of the $661 \mathrm{~W}$ photoreceptor cells were decreased while ROS content was increased when the cells were treated with light alone $(P<0.05)$. The CERKL mRNA level was increased $(P<0.01)$ while ROS content was decreased $(P<0.05)$ when the $661 \mathrm{~W}$ photoreceptor cells were treated with BDNF alone. The addition of BDNF led to an obvious attenuation in the light-induced increase of ROS content, as well as the light-induced decrease of CERKL mRNA level and cell viability of the $661 \mathrm{~W}$ photoreceptor cells $(P<0.05)$.

Retinal degeneration is one of the main causes of blindness worldwide. Although a wide variety of etiologies have been attributed to retinal degeneration, photoreceptor cell death is the final common pathological change and the main therapeutic target ${ }^{1}$. As an important factor of retinal degeneration, light injury is often used to simulate retinal degeneration in mammalian models ${ }^{3-5}$. It is generally recognized that excessive oxidative stress is involved in the retinal injury induced by constant light stimulation $^{1}$. Evidence suggests that light can increase ROS content and suppress the viability of retinal pigment
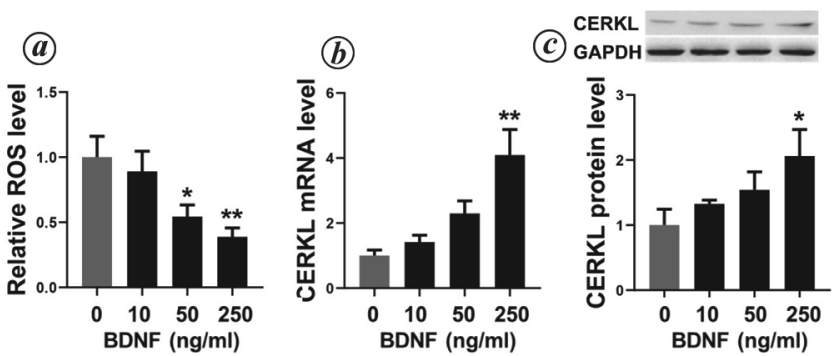

Figure 3. ROS and CERKL gene expression. The cells were treated with light of 2500 lux and $0,10,50$ and $250 \mathrm{ng} / \mathrm{ml}$ brain-derived neurotrophic factor (BDNF) for $24 \mathrm{~h}$. $\boldsymbol{a}$, ROS content in the $661 \mathrm{~W}$ cells; $\boldsymbol{b}$, mRNA level of CERKL in the $661 \mathrm{~W}$ cells. $c$, Protein level of CERKL in the $661 \mathrm{~W}$ cells. ${ }^{*} P<0.05, * * P<0.01$ versus control. $N \geq 3$.
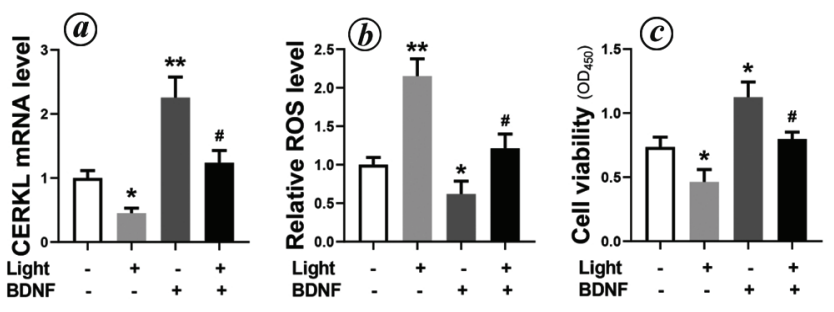

Figure 4. CERKL gene expression and ROS. The cells were treated with light of $2500 \mathrm{lux}$ and/or $250 \mathrm{ng} / \mathrm{ml} \mathrm{BDNF}$ for $24 \mathrm{~h}$. $\boldsymbol{a}$, mRNA and protein level of CERKL in the $661 \mathrm{~W}$ cells; $\boldsymbol{b}$, ROS content in the $661 \mathrm{~W}$ cells. $c$, Cell viability of the $661 \mathrm{~W}$ cells. $* P<0.05,{ }^{*} P<0.01$ versus control. ${ }^{\#} P<0.05,{ }^{\# \#} P<0.01$ versus the light group. $N \geq 5$. 


\section{RESEARCH COMMUNICATIONS}

epithelial cells in an intensity-dependent manner ${ }^{2}$. King et $a l .{ }^{14}$ found that blue light exposure induced ROS production and death of ARPE-19 cells, which were blocked by mitochondria-specific antioxidants. Consistent with this, results from the present study demonstrate that light stimulation decreased cell viability of $661 \mathrm{~W}$ photoreceptor cells in a time- and intensity-dependent manner, and increased ROS content in the cells in a time-dependent manner. In conclusion, ROS accumulation induced by light exposure may be an important cause of photoreceptor apoptosis and retinal degeneration.

CERKL is essential for retinal development, protecting the retinal cells from excessive oxidative stress-induced apoptosis. CERKL gene mutations are responsible for a severe phenotype of hereditary retinal degeneration, characterized by early and prominent loss of macular cone and rod photoreceptors, resulting in a deficit in both peripheral and central vision ${ }^{6,7}$. Li et al. ${ }^{8}$ reported that knockdown of CERKL gene in the zebrafish led to an increase in photoreceptor apoptosis and retinal degeneration development. Further studies revealed that downregulation of CERKL rendered retinal cells more susceptible to oxidative stress, whereas overexpression of CERKL protected the cells from oxidative stress-induced apoptosis through interacting with mitochondrial thioredoxin-2. These results indicate that CERKL mutation may induce photoreceptor apoptosis by increasing the sensitivity to oxidative stress. In line with this, the present study found that constant light exposure can increase ROS production in photoreceptor cells in a time-dependent manner. Meanwhile, CERKL expression was also inhibited. Therefore, one may suggest that constant treatment with high-intensity light stimulates the accumulation of ROS through suppressing CERKL gene expression, and consequently induces apoptosis of photoreceptors.

As a member of the neurotrophin family of growth factors, BDNF plays an important role in modulating the development, differentiation, survival, regeneration, repair and functioning of central and peripheral neurons. Thus, BDNF is widely used in the prevention and delaying of neurodegenerative diseases ${ }^{15}$. Studies showed that both intraocular injection and topical eye application of BDNF protects photoreceptors from light-induced damage $^{9}$. It has been demonstrated that BDNF can also protect auditory neurons from cisplatin toxicity by decreasing ROS production ${ }^{16}$. The present study revealed that exogenous BDNF supplement could upregulate CERKL expression and decrease ROS production in photoreceptors exposed to constant high-intensity light.

In conclusion, constant treatment with high-intensity light suppresses the gene expression of CERKL, stimulates the accumulation of ROS, and consequently induces apoptosis of photoreceptors, while BDNF could protect the photoreceptors from light-induced injury through upregulating the gene expression of CERKL and downregulating the accumulation of ROS.
Conflict of interest: The authors declare no conflict of interest.

1. Wert, K. J., Lin, J. H. and Tsang, S. H., General pathophysiology in retinal degeneration. Dev. Ophthalmol., 2014, 53, 33-43.

2. Nakanishi-Ueda, T. et al., Blue LED light exposure develops intracellular reactive oxygen species, lipid peroxidation, and subsequent cellular injuries in cultured bovine retinal pigment epithelial cells. Free Radic. Res., 2013, 47, 774-780.

3. Niwa, M., Aoki, H., Hirata, A., Tomita, H., Green, P. G. and Hara, A., Retinal cell degeneration in animal models. Int. J. Mol. Sci., 2016, 17(1).

4. Grewal, R., Organisciak, D. and Wong, P., Factors underlying circadian dependent susceptibility to light induced retinal damage. Adv. Exp. Med. Biol., 2006, 572, 411-416.

5. Wenzel, A., Grimm, C., Samardzija, M. and Remé, C. E., Molecular mechanisms of light-induced photoreceptor apoptosis and neuroprotection for retinal degeneration. Prog. Retin. Eye Res., 2005, 24, 275-306.

6. Vekslin, S. and Ben-Yosef, T., Spatiotemporal expression pattern of ceramide kinase-like in the mouse retina. Mol. Vis., 2010, 16, 2539-2549.

7. Bornancin, F. et al., Characterization of a ceramide kinase-like protein. Biochim. Biophys. Acta, 2005, 1687, 31-43.

8. Li, C. et al., CERKL interacts with mitochondrial TRX2 and protects retinal cells from oxidative stress-induced apoptosis. Biochim. Biophys. Acta, 2014, 1842, 1121-1129.

9. Cerri, E. et al., Conjunctivally applied BDNF protects photoreceptors from light-induced damage. Transl. Vis. Sci. Technol., 2015, 4,1 .

10. Aleman, T. S. et al., CERKL mutations cause an autosomal recessive cone-rod dystrophy with inner retinopathy. Invest. Ophthalmol. Vis. Sci., 2009, 50, 5944-5954.

11. Harada, T. et al., Modification of glial-neuronal cell interactions prevents photoreceptor apoptosis during light-induced retinal degeneration. Neuron, 2000, 26, 533-541.

12. Harada, T. et al., Microglia-Müller glia cell interactions control neurotrophic factor production during light-induced retinal degeneration. J. Neurosci., 2002, 22, 9228-9236.

13. Kano, T., Abe, T., Tomita, H., Sakata, T., Ishiguro, S. and Tamai, M., Protective effect against ischemia and light damage of iris pigment epithelial cells transfected with the BDNF gene. Invest. Ophthalmol. Vis. Sci., 2002, 43, 3744-3753.

14. King, A., Gottlieb, E., Brooks, D. G., Murphy, M. P. and Dunaief, J. L., Mitochondria-derived reactive oxygen species mediate blue light-induced death of retinal pigment epithelial cells. Photochem. Photobiol., 2004, 79, 470-475.

15. Abed, E., Corbo, G. and Falsini, B., Neurotrophin family members as neuroprotectants in retinal degenerations. BioDrugs, 2015, 29, $1-13$.

16. Gabaizadeh, R., Staecker, H., Liu, W. and Van De Water, T. R., BDNF protection of auditory neurons from cisplatin involves changes in intracellular levels of both reactive oxygen species and glutathione. Mol. Brain Res., 1997, 50, 71-78.

ACKNOWLEDGMENT. This work was supported by grants from the National Natural Science Foundation of China (No. 81603214).

Received 7 September 2019; revised accepted 15 January 2021

doi: $10.18520 / \mathrm{cs} / \mathrm{v} 120 / \mathrm{i} 6 / 1088-1091$ 